\title{
The Effect of Pendelluft and Dead Space on Nitrogen Clearance: Mathematical and Experimental Models and their Application to the Study of the Dis- tribution of Ventilation*
}

\author{
Ivan Safonoff and George E. Em manuel \\ (From the Department of Medicine, State University of New York, Downstate Medical Center \\ and the Kings County Hospital Center, Brooklyn, New York)
}

Summary. Reinspired mixed dead space gas and Pendelluft may be considered to be part of a single process of interalveolar gas transfer. The effect of interalveolar gas transfer on nitrogen clearance from a two chamber lung model can be described by a single set of equations which hold for synchronous, and series ventilation.

Interalveolar gas transfer may theoretically be either bidirectional or unidirectional. Bidirectional transfer results in an underestimation of the effective ventilation and volume of the well-ventilated compartment when nitrogen washout is analyzed by available methods. The volume of the poorly ventilated compartment is overestimated and its effective ventilation is usually overestimated but may be correctly or underestimated as distribution becomes more uneven. Unidirectional transfer has the same qualitative effect except that the ventilation of the poorly ventilated space is always overestimated. The distortions produced by both types of gas transfer become less marked as ventilation becomes more uneven.

Nitrogen washout data from a model consisting of two rubber balloons conneceted with a $Y$ tube agree well with the mathematical predictions. Application of the theory to data obtained from patients with advanced chronic obstructive lung disease suggests that estimates of the functional residual capacity and of the volume and ventilation of the poorly ventilated spaces are not greatly affected by interalveolar gas transfer when nitrogen washout is analyzed by usual methods.

\section{Introduction}

Pendelluft is a term used to describe the hypothetical transfer of alveolar gas between groups of alveoli with different mechanical time constants

\footnotetext{
* Received for publication 23 March 1967 and in revised form 12 June 1967.

This study was supported in part by the Health Research Council of The City of New York, Grants $\mathrm{U}-1486, \mathrm{U}-1361$, and $\mathrm{U}-1642$ and in part by the $\mathrm{Na}-$ tional Heart Institute Grants $\mathrm{HE}-05757$ and $5 \mathrm{~T} 12 \mathrm{HE}-$ 0.5726.

Address requests for reprints to Dr. George E. Emmanuel, Department of Medicine, State University of New York, Downstate Medical Center, 450 Clarkson Avenue, Brooklyn, N. Y. 11203.
}

and consequently asynchronous ventilation. The mechanism by which Pendelluft may occur has been described in detail by Otis and coworkers (1). Although Pendelluft has not been demonstrated, convincing evidence has been presented in favor of the occurrence of widely varying mechanical time constants in the lungs of patients with obstructive lung disease $(1,2)$.

It is evident from the anatomy of the lung that alveoli contributing gas of different composition to a common dead space on expiration must reinspire part of this gas mixture during the following inspiration even if ventilation is synchronous. Thus both Pendelluft and inspiration of common 


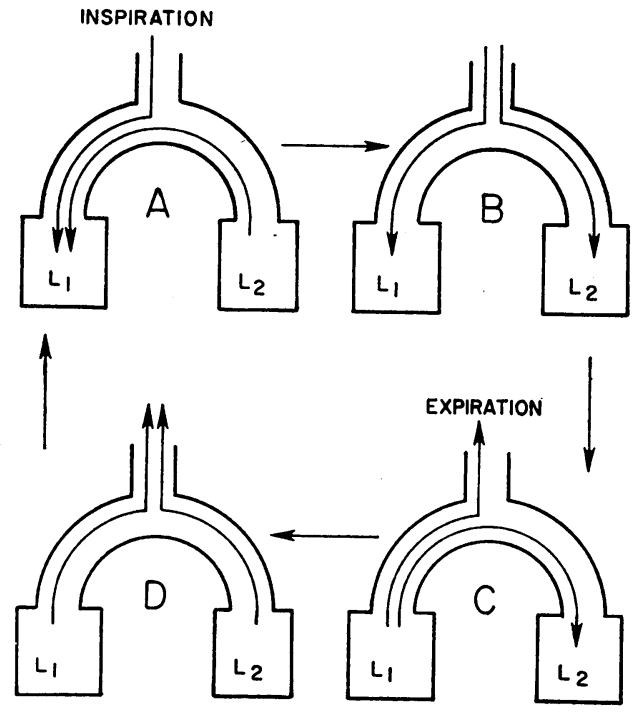

Fig. 1. Diagram of the sequence of the mechaniCAL EVENTS OF A TWO COMPARTMENT EXPERIMENTAL MODEL DURING A RESPIRATORY CYCLE. The two compartments are out of phase so that the gas transfer between the two compartments occurs during each phase of a respiratory cycle (see text).

dead space gas are part of the same general process, namely the transfer of gas between groups of alveoli.

The purpose of the present study was to investigate the effect of Pendelluft and of mixed dead space gas on the clearance of nitrogen in a two compartment mathematical model and a two compartment alinear experimental model and to consider the possible errors that arise when clearance curves of nitrogen are used for estimating uneven ventilation of the lungs.

\section{Methods}

Theory. Let us consider the model of Otis (1), in which two balloons of different compliances are ventilated cyclically through a $\mathrm{Y}$ tube whose limbs have unequal flow resistance. Over a wide range of ventilatory frequencies the flows and tidal volumes will be out of phase in such a manner that the elements with greater product of resistance and compliance will lag behind the other balloon in relation to the events at the "mouth."

Fig. 1 diagrammatically represents the sequence of gas flows in such a model during a ventilatory cycle. Balloon $L_{2}$ lags behind balloon $L_{1}$. Now assume that the model originally contained $80 \%$ nitrogen and the nitrogen is now being washed out by ventilating the model with $100 \%$ oxygen. Since $L_{8}$ receives a smaller proportion of the effective ventilation in relation to its volume than $L_{1}$, the washout of nitrogen from $L_{z}$ will be slower than that from $L_{1}$. At the onset of inspiration $(A)$ at the outlet, $L_{2}$ is still expiring. $L_{t}$ thus inspires its own dead space nitrogen, Pendelluft from $L_{2}$ with a higher nitrogen concentration, and a large proportion of the common dead space which contains nitrogen from $L_{2}$ of the same concentration as the Pendelluft. It is even possible that $L_{1}$ will inspire all of the common dead space gas; this will depend on the relative size of the dead space, the size and shape of the tidal volume curve for $L_{1}$, and the degree of the phase shift between the two balloons. Thus when $L_{z}$ begins its inspiration $(B)$, it receives nitrogen from its own dead space but may receive little or no nitrogen from the common dead space. From $(B)$ to $(C)$ both balloons are receiving $100 \%$ oxygen. When expiration begins at the common outlet $(C), L_{1}$ is expiring but $L_{z}$ is still inspiring and during this time Pendelluft from $L_{1}$ to $L_{2}$ occurs. But before any nitrogen-containing gas can reach $L_{\ell}$, oxygen must first enter $L_{\ell}$, in an amount at least equal to the volume of the separate dead space of $L_{\mathbf{2}}$. When and if Pendelluft from $L_{1}$ to $L_{\mathbf{z}}$ enters $L_{\mathbf{2}}$, its nitrogen concentration will be lower at all times than the concentration in $L_{2}$. From $(D)$ to $(A)$ both balloons are expiring and contributing varying amounts of nitrogen to the outside and the common dead space until inspiration $(A)$ is again initiated.

Several conclusions are apparent from the foregoing description: the phenomenon of asynchronous ventilation tends to increase the dead space ventilation and decrease the effective ventilation of the better ventilated balloon $L_{1}$ and to decrease the dead space ventilation and increase the effective ventilation of the more poorly ventilated balloon $L_{2}$. The same conclusions would apply for nitrogen washout or steady-state, room air breathing, if the balloons were in reality two dissimilar groups of alveoli with different ventilation perfusion ratios.

Now assume that the model in Fig. 1 is being continuously ventilated, initially with room air and then with $100 \%$ oxygen (open circuit nitrogen washout for continuous ventilation). Let $x=$ the concentration of nitrogen in $L_{1}$ at any time, $t$, during $100 \%$ oxygen breathing, $y=$ the concentration of nitrogen in $L_{z}$ at any time, $t$, during $100 \%$ oxygen breathing, $L_{1}, L_{2}=$ the volume of the compartments in liters, $\nabla_{A_{1}}, V_{A_{2}}=$ the effective expiratory ventilation of $L_{1}, L_{\mathbf{s}}$ in liters/minute, $\mathrm{VE}=$ total ventilation leaving the system in liters/minute, $V p_{1}=$ the rate in liters/minute, at which gas enters $L_{2}$ from $L_{1}$ as Pendelluft and/or from the common dead space, and $V \mathrm{p}_{2}=$ the rate in liters/minute at which gas enters $L_{1}$ from $L_{8}$ as Pendelluft and/or from the common dead space. $\nabla_{\mathrm{A}_{1}} / L_{1}=k_{1}, \mathrm{VA}_{\mathrm{A}_{2}} / L_{2}=k_{2}, \mathrm{Vp}_{2} / L_{1}=p_{1}$, and $\mathrm{V}_{p_{1}} /$ $L_{2}=p_{2}$. Then the rate at which the amount of nitrogen is changing in $L_{1}$ and $L_{2}$ during washout is equal to the rate at which nitrogen enters minus the rate at which nitrogen leaves each space, or

$$
\begin{aligned}
L_{1} \mathrm{~d} x / \mathrm{d} t & =\dot{\mathrm{V}} \mathrm{p}_{2} y-\dot{\mathrm{V}}_{\mathrm{A}_{1} x} \\
L_{2} \mathrm{~d} x / \mathrm{d} t= & \dot{\mathrm{V}}_{\mathrm{p}_{1} x} x-\dot{\mathrm{V}}_{\mathrm{A}_{2}} y .
\end{aligned}
$$

Dividing equation 1 by $L_{1}$ and equation 2 by $L_{2}$ and sub- 
stituting $k_{1}, k_{2} ; p_{1}, p_{2}$ gives:

$$
\begin{aligned}
& \mathrm{d} x / \mathrm{d} t=p_{1} y-k_{1} x \\
& \mathrm{~d} y / \mathrm{d} t=p_{2} x-k_{2} y .
\end{aligned}
$$

Then it can be shown that

$$
\begin{aligned}
& x=C_{1} \mathrm{e}^{m_{1} t}+C_{2} \mathrm{e}^{m_{2} t} \\
& y=C_{3} \mathrm{e}^{m_{1} t}+C_{4} \mathrm{e}^{m_{2} t},
\end{aligned}
$$

where at $t=0, x=y=X_{0}=Y_{0}=$ the initial concentration of nitrogen hereafter defined as $F_{N_{20}}$ and $e$ is the base of the natural logarithmic system, and

$$
\begin{aligned}
m_{1}, m_{2} & =\left(\frac{1}{2}\right)\left[-\left(k_{1}+k_{2}\right) \pm \sqrt{\left(k_{1}-k_{2}\right)^{2}+4 p_{1} p_{2}}\right] \\
C_{1} & =F_{2_{20}}\left(k_{1}+m_{2}-p_{1}\right) /\left(m_{2}-m_{1}\right) \\
C_{2} & =F_{20}\left(p_{1}-m_{1}-k_{1}\right) /\left(m_{2}-m_{1}\right) \\
C_{3} & =F_{2_{20}}\left(k_{2}+m_{2}-p_{2}\right) /\left(m_{2}-m_{1}\right) \\
C_{4} & =\mathrm{FN}_{20}\left(p_{2}-m_{1}-k_{2}\right) /\left(m_{2}-m_{1}\right) \\
\text { for } k_{1} & \neq k_{2} .
\end{aligned}
$$

The use of the terms $\nabla p_{1}, \forall p_{2}$ should be further clarified. If ventilation is synchronous and there is no Pendelluft, $V \mathrm{p}_{1}, \mathrm{~V}_{\mathrm{p}_{2}}$ will represent the flow rate of gas transferred between $L_{1}$ and $L_{2}$ as a consequence of reinspiring the common dead space mixture. $\nabla p_{1}, V p_{2}$ can then be determined if the size of the common dead space, the fraction of the dead space contributed by $L_{1}, L_{2}$, and the fraction of the dead space mixture inspired by $L_{1}, L_{2}$ are known. $V p_{1}, V_{p_{2}}$ may also be used to represent the flow rate of the Pendelluft alone in the absence of a common dead space or the combined flow of Pendelluft and dead space gas as determined above.

It should also be noted that $\nabla p_{1}, \nabla_{p_{2}}$ cannot exceed $V_{A_{2}}$, the lesser of the two effective ventilations. If $V_{p_{1}}=V_{p_{2}}=\nabla_{A_{2}}$, all the ventilation to and from the poorly ventilated balloon, $L_{2}$, must first pass through the well-ventilated balloon, $L_{1}$. This of course would mean that $L_{1}$ and $L_{2}$ are ventilating 180 degrees out of phase much as the lungs would be during paradoxical respiration due to chest injuries. Furthermore this special case is an example of "series ventilation," and nitrogen decays in exactly the same way as in the model analyzed by Robertson, Siri and Jones (3). Since $\nabla p_{1}=V p_{2}=$ $\nabla_{A_{2}}, p_{1}$ will equal $k_{2}, p_{2}$ is the same as Robertson's constant $k_{3}$, and our constant $k_{1}$ is equivalent to Robertson's $k_{1}+k_{3}$. Substitution of these factors into the expressions for $m$ and $C$ in equations 5 and 6 gives the same solution for "series ventilation" as that described by Robertson, Siri, and Jones.

Thus equations 5 and 6 are a general solution for the decay of nitrogen in a two compartment system with asynchronous, "parallel," or "series ventilation," with or without dead space effect.

The equation for mixed expired concentration $\left(\mathrm{F}_{\mathrm{E}_{2}}\right)$ at any time $t$ is :

$$
\begin{aligned}
\mathrm{F}_{\mathrm{E}_{\mathrm{N}_{2}}}=\left[\left(\dot{\mathrm{V}}_{\mathrm{A}_{1}}-\dot{\mathrm{V}}_{\mathrm{p}_{1}}\right)(x) / \mathrm{V} \mathrm{E}\right] & \\
+ & {\left[\left(\dot{\mathrm{V}}_{\mathrm{A}_{2}}-\dot{\mathrm{V}}_{\mathrm{p}_{2}}\right)(y) / \dot{\mathrm{V}} \mathrm{E}\right] }
\end{aligned}
$$

This is contrasted with the usual "parallel ventilation" equation $(V p=0)$ for mixed expired nitrogen, which for a two compartment system is :

$$
\mathrm{FE}_{\mathrm{N}_{2 t}}=\left[\mathrm{FN}_{20} \dot{\mathrm{VA}}_{\mathrm{A}_{1}} \mathrm{e}^{-k_{1} t}+\mathrm{FN}_{20} \dot{\mathrm{VA}}_{2} \mathrm{e}^{-k_{2} t}\right] / \dot{\mathrm{V}} \mathrm{E} .
$$

When data from a washout are plotted against time on a semilogarithmic scale and the separate exponentials are found and extrapolated to zero time, the intercepts $\left(I_{1}\right.$, $\left.I_{2}\right)$ and turnover rates $\left(k_{1}, k_{2}\right)$ can be used to calculate $\nabla_{A_{1}}, V_{A_{2}}$ and $L_{1}, L_{2}$ from:

$$
\begin{gathered}
\dot{\mathrm{V}}_{\mathrm{A}_{1}}, \dot{\mathrm{V}}_{\mathrm{A}_{2}}=\left(I_{1}, I_{2}\right)\left(\dot{\mathrm{V}}_{\mathrm{E}}\right) /\left(\mathrm{FN}_{2_{0}}\right) \\
L_{1}, L_{2}=\left(I_{1}, I_{2}\right)(\dot{\mathrm{VE}}) /\left(\mathrm{FN}_{2_{0}}\right)\left(k_{1}, k_{2}\right) .
\end{gathered}
$$

If there is Pendelluft and/or reinspiration of mixed dead space gas and the data from a washout are analyzed according to equations $8-10$, the apparent ventilations and volumes will be given by:

apparent

$$
\dot{\mathrm{V}}_{\mathrm{A}_{1}}=\left[\left(\dot{\mathrm{V}}_{\mathrm{A}_{1}}-\dot{\mathrm{V}}_{\mathrm{p}_{1}}\right) C_{2}+\left(\dot{\mathrm{V}}_{\mathrm{A}_{2}}-\dot{\mathrm{V}}_{2}\right) C_{4}\right] / \mathrm{FN}_{2_{0}}
$$

apparent

$$
\begin{aligned}
\dot{\mathrm{V}}_{\mathrm{A}_{2}}= & {\left[\left(\dot{\mathrm{V}}_{\mathrm{A}_{1}}-\dot{\mathrm{V}}_{\mathrm{p}_{1}}\right) C_{1}+\left(\dot{\mathrm{V}}_{\mathrm{A}_{2}}-\dot{\mathrm{V}}_{\mathrm{p}_{2}}\right) C_{3}\right] / \mathrm{FN}_{2_{0}} } \\
& \text { apparent } L_{1}=\text { equation } 11 \div\left(-m_{2}\right) \\
& \text { apparent } L_{2}=\text { equation } 12 \div\left(-m_{1}\right) .
\end{aligned}
$$

Further consideration of the events represented in Fig. 1 suggest another possibility: if $L_{1}$ inspires all of the common dead space gas and if the phase shift, the tidal volume of $L_{2}$ and/or the Pendelluft from $L_{1}$ to $L_{2}$ are small enough, then gas from $L_{1}$ will not enter $L_{2}$. This means that gas transfer between the compartments is unidirectional and $V p_{1}=0$. When $\nabla p_{1}$ and hence $p_{2}=0$, equations 5 and 6 are reduced to:

$$
\begin{aligned}
& x=\mathrm{FN}_{20}\left[1-\left(\dot{\mathrm{V}}_{2} / L_{1}\right)\left(k_{1}-k_{2}\right) e^{-k_{1} t}\right] \\
& +\mathrm{FN}_{20}\left(\dot{\mathrm{V}}_{2} / L_{1}\right)\left(k_{1}-k_{2}\right) \mathrm{e}^{-k_{2} t} \\
& y=\mathrm{FN}_{2_{0}} \mathrm{e}^{-k_{2} t},
\end{aligned}
$$

indicating that the nitrogen in $L_{1}$ decays as the sum of two exponentials and the nitrogen in $L_{2}$ decays as a single exponential. Then, in a manner similar to that for derivation of equations 11-14, the apparent volumes and effective ventilations are given by:

$$
\begin{aligned}
& \text { apparent } \dot{\mathrm{V}}_{\mathrm{A}_{1}}=\dot{\mathrm{V}}_{\mathrm{A}_{1}}-\dot{\mathrm{V}} \mathrm{p}_{2}\left[k_{1} /\left(k_{1}-k_{2}\right)\right] \\
& \text { apparent } L_{1}=\text { equation } 17 \div k_{1} \\
& \text { apparent } \dot{\mathrm{V}}_{\mathrm{A}_{2}}=\dot{\mathrm{V}}_{\mathrm{A}_{2}}+\dot{\mathrm{V}}_{2}\left[k_{1} /\left(k_{1}-k_{2}\right)-1\right] \\
& \text { apparent } L_{2}=\text { equation } 19 \div k_{2}, \\
& \text { where } k_{1} \neq k_{2} \text { and the fraction } k_{1} /\left(k_{1}-k_{2}\right)>1 .
\end{aligned}
$$

The results of five hypothetical washouts with bidirectional gas transfer are shown in Fig. 2. $\nabla \mathrm{p}_{1}=$ $\nabla_{p_{2}}=0.5$ liters $/ \mathrm{min}, \nabla_{A_{1}}=5$ liters $/ \mathrm{min}, \nabla_{A_{2}}=1$ liter $/$ min and the sum $L_{1}+L_{2}$ is constant at 6 liters. $L_{1}$ and $L_{2}$ are varied in each washout thus causing $k_{1}, k_{2}$ and $p_{1}$, $p_{2}$ to vary. If the washouts were analyzed in the conventional manner, both the volume and the effective ventilation of the well-ventilated compartment $L_{1}$ are always underestimated. $\nabla_{\mathrm{A}_{2}}$, however, is usually overestimated; 


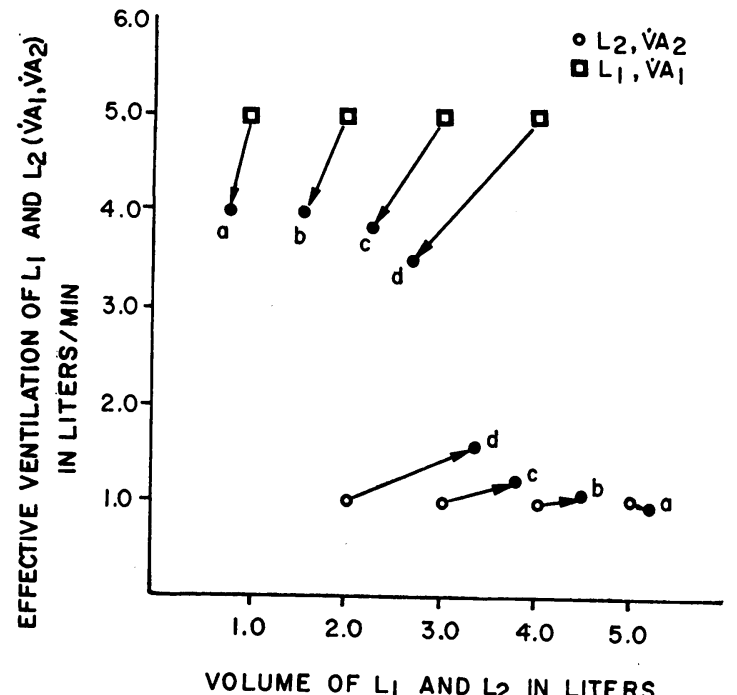

Fig. 2. EFFECT OF BIDIRECTIONAL GAS TRANSFER (W HERE $\left.V \mathrm{p}_{1}=V \mathrm{p}_{2}\right)$ ON THE APPARENT VOLUME AND VENTILATION OF EACH OF A TWO COMPARTMENT MATHEMATICAL MODEL. In each case the squares and circles represent actual values. The dots at the tip of the arrows represent the apparent values. Each pair of letters, i.e. $a a, b b$, etc., represents the results of a single hypothetical washout.

but as the distribution of ventilation becomes more uneven, $\nabla_{A_{2}}$ may become slightly underestimated. $L_{2}$ is overestimated, but only minimally, when the distribution of ventilation is very uneven. The total effective ventila-

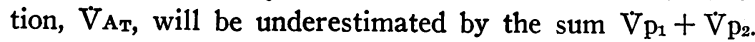

Fig. 3 is constructed similarly to Fig. 2, but gas transfer is unidirectional from $L_{2}$ to $L_{1}$. The values of the parameters in each of four washouts are the same as above except $V \mathrm{p}_{1}=0$. Again $V \mathrm{~A}_{1}$ and $L_{1}$ will be underestimated. $\nabla_{\mathrm{A}_{2}}$ and $L_{2}$ are both overestimated. The errors become worse as distribution becomes more even. $\mathrm{V}_{\mathrm{A}_{t}}$ is underestimated by an amount equal to $\mathrm{V}_{\mathrm{p}_{2}} . k_{1}$ and $k_{2}$ as well as LT would be correctly estimated. The effects are also apparent from an examination of equations $17-20$.

All the preceeding theoretical considerations apply to a model with linear properties. In actual practice however, we are frequently concerned with analyzing nonlinear systems such as the human lung. Therefore an alinear physical model was constructed and its behavior was studied during nitrogen washout.

Experimental model. Two ends of a metal $\mathrm{Y}$ tube of 3. inch internal diameter were fitted with two Statham pneumotachographs (Statham Instruments, Inc., Los Angeles, Calif.; flow linear from 0 to 150 liters $/ \mathrm{min}$ ), as shown in Fig. 4. The two free ends of the pneumotachographs were in turn fitted with rubber anesthesia balloons $L_{1}$ and $L_{2}$, which had capacities of 5 and 15 liters respectively. "Capacity" refers to the volume of gas each rubber anesthesia bag can hold before the rubber starts to stretch. In addition the balloons are constructed so that the rubber at the four seams of each balloon is almost twice the thickness of the walls of the balloon.

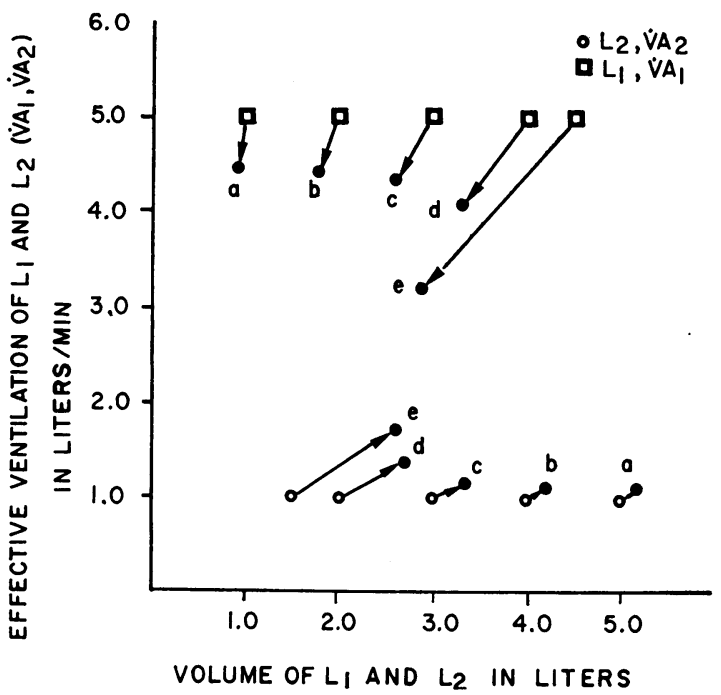

Fig. 3. EFFECT OF UNIDIRECTIONAL GAS TRANSFER (WHERE $V \mathrm{p}_{1}=0$ ) ON THE APPARENT VOLUME AND VENTILATION OF EACH OF A TWO COMPARTMENT MATHEMATICAL MODEL. In each case the squares and circles represent actual values. The tip of the arrows represent actual values. Each pair of letters, i.e. $a a, b b$, etc., represents the results of a single hypothetical washout.

These properties result in alinear compliance. All fittings were composed of sections of thick walled, wide bore rubber tubing so that the balloons and pneumotachographs could be easily removed and replaced. An obstruction was inserted in the arm of the $\mathrm{Y}$ tube holding the 15 liter balloon, a rubber bottle stopper with a bore hole varying in diameter from $\frac{7}{3^{2}}$ to $\frac{7}{16}$ inch. A narrow, ragged, untapered bore in the rubber bottle stopper was used to create nonlaminar flow and alinear flow resistance. The total volume of the "dead space" of the model was $300 \mathrm{ml}$ and that of each limb $100 \mathrm{ml}$. The model was ventilated by a Bird Mark 7 respirator (Bird Corp. Ltd., Richmond, Calif.). Initially the model was ventilated with compressed room air. At the end of an expiration at the common outlet clamps were simultaneously placed at the junction of each balloon with the pneumotachograph as well as at the junction of the common dead space of the model with the Bird respirator. The respirator was then flushed with $100 \%$ oxygen and reconnected to the model and the nitrogen washout study was performed. 30-sec samples of mixed expired gas were collected and analyzed for nitrogen concentration by a method previously described (4). During the experiments sampling needles connected to the nitrogen meter were inserted in the orifices of both balloons so that the nitrogen concentration of the mixed expired gas and the concentration of nitrogen at the outlet of each balloon could be alternately measured. A continuous record was made of air flow and tidal volume obtained by electrical intergration of the flow signal of each balloon.

Calculations. The log of the nitrogen concentration of the $30-\mathrm{sec}$ mixed expired gas samples was plotted against 
time on the $\mathrm{x}$ axis. The volume $L_{2}$ and effective ventilation $\mathrm{V}_{\mathrm{A}_{2}}$ of the large balloon were calculated according to equations 9 and 10 . The total volume $L_{T}$ was calculated by the method described by Emmanuel, Briscoe, and Cournand (5). The total effective minute ventilation $\left(\nabla \mathbf{A T}_{\mathbf{T}}\right.$ ) was determined by subtracting the ventilation of the total dead space (VD) from the total expired minute ventilation VE. The volume, $L_{1}$, of the small balloon was determined from the difference between the total volume of the model and the volume of the large balloon. The effective ventilation, $V_{A_{1}}$, of the small balloon was similarly determined from the difference of the total effective ventilation and the effective ventilation from the large balloon. Pendelluft was measured from the simultaneous record of the separate tidal volumes.
The expected or actual values of effective ventilation, $\mathrm{V}_{\mathbf{A}_{1}}+\mathrm{V}_{\mathrm{A}_{2}}$ were estimated from the records of tidal volume and tidal nitrogen concentration of each balloon.

\section{Results}

Fig. 5 represents the simultaneously recorded tidal volume of each balloon in one of the studies. The height of the shaded triangles is the volume of the Pendelluft and the base of the triangles equals the time in seconds that Pendelluft occurs. The small upper left hand triangle represents the Pendelluft going from $L_{1}$ to $L_{2}$, and the other larger triangle the Pendelluft in the opposite direction, $L_{2}$ to $L_{1}$.

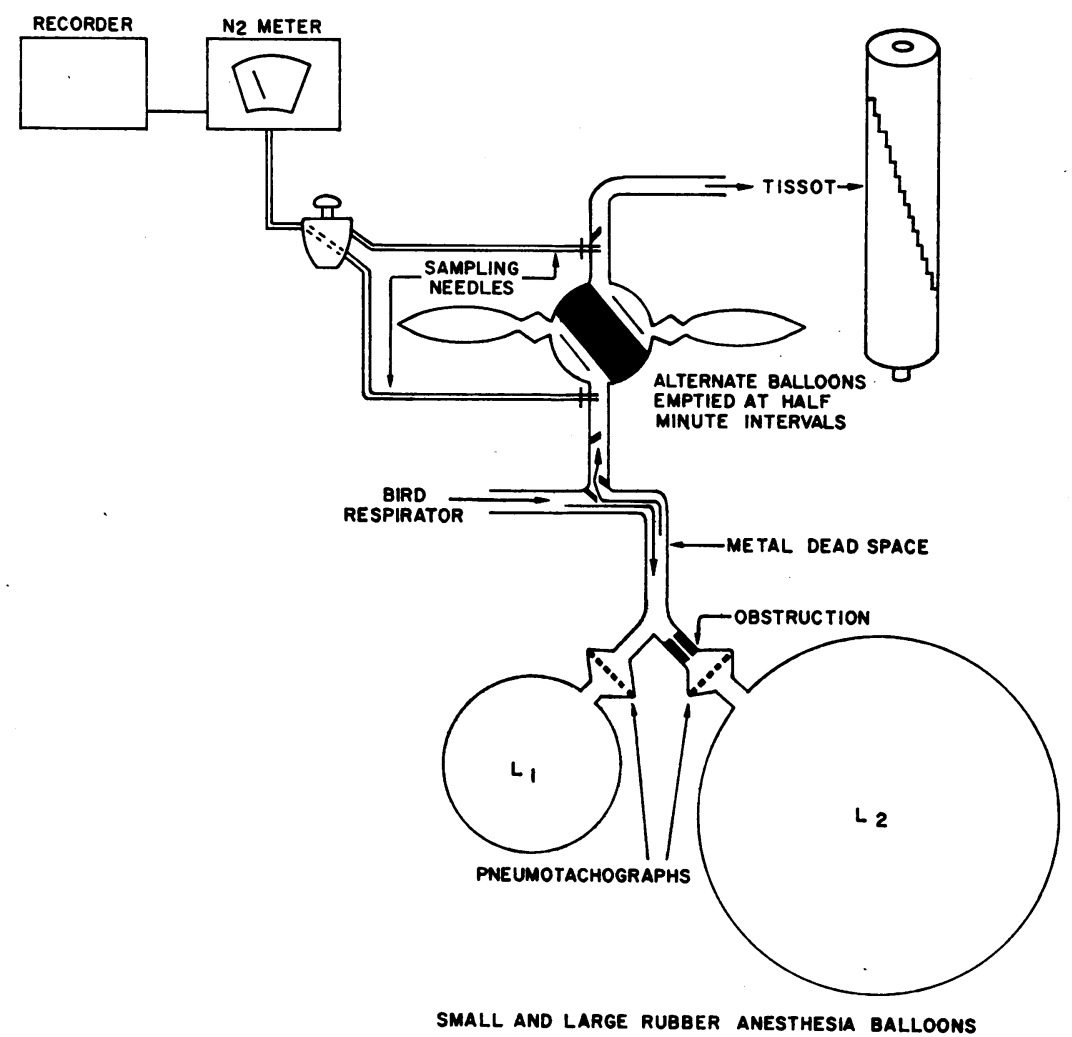

Fig. 4. Diagrammatic RePresentation of a tWo COMPARTMENT EXPERIMENTAL MODEL CONNECTED IN PARALlel AND veNTILTEd BY A MARK 7 Bird Respirator. Mixed expired gas is collected into a two balloon sampling system and emptied into a Tissot gasometer alternately at half-minute intervals. The dead space of the valve connected to the two balloons is $60 \mathrm{ml}$. One of the two sampling needles connected to a $300 \mathrm{AR}$ nitrogen meter through a threeway stopcock is alternately inserted in the orifice of each of the two rubber anesthesia balloons and in the outlet of the common dead space, the other remaining in the mixed expired side of the two balloon system. Air flow was determined by the pneumotachograph placed between the orifice of each balloon and the common dead space and tidal volume determined by electrical integration of the flow signal. 


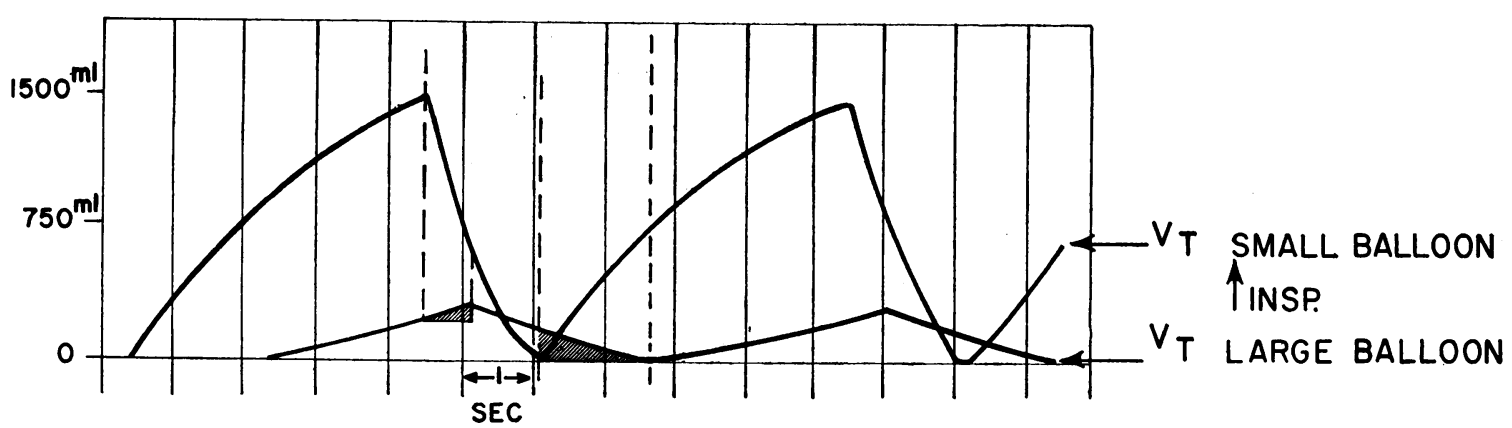

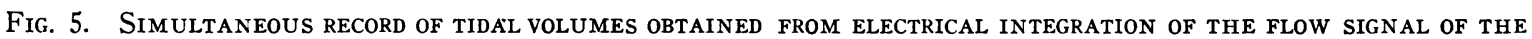
PNEUMOTACHOGRAPH OF EACH BALLOON OF A TWO COMPARTMENT EXPERIMENTAL MODEL SHOWN IN FIG. 4.

It can be seen that the quantity of Pendelluft is dependent not only on the phase difference and size of the tidal volume curves but also on the relative length of inspiration and expiration and on the shape of each curve during the time Pendelluft is occurring.

Nitrogen changes at three points in the model are shown in Fig. 6 and explained in the legend. The concentration of nitrogen at the time nitrogen reached a good plateau on expiration was used to plot the decay curve of each balloon.

The decay curve of nitrogen in the mixed expired air and the decay curves of nitrogen in each balloon during the same washout are shown in Figs. 7A and 7B respectively. The slow phase of nitrogen elimination is parallel in both balloons and the mixed expired gas, as expected. It can also be seen that the well-ventilated balloon, $L_{1}$, contains significant amounts of nitrogen during the washout which may almost equal the concentration of nitrogen in the mixed expired air.

The results of nine nitrogen washout studies are shown in Table I. Studies 1 and 2 are duplicate washouts and indicate that the results are reproducible. Slow ventilatory frequencies were chosen in order to maximize the possible difference between cyclic ventilation and the assumption that ventilation is continuous. Despite the alinearities of the system and the slow cyclic ventilation, the estimated values of volume and effective ventilation agree fairly well with the theoretical predictions. In studies 1-7 gas transfer was considered to be only from $L_{2}$ to $L_{1}$ for the reasons already described. $\nabla_{A_{2}}$ and $L_{2}$ tend to be slightly overestimated and $V_{A_{1}}$ and $L_{1}$ significantly underestimated. Where gas transfer is bidirectional in studies 8 and $9, V_{\mathrm{A}_{1}}$ and $L_{1}$ are again underesti- mated. $\vec{V}_{A_{2}}$ is very slightly underestimated, as suspected. $L_{2}$ is insignificantly underestimated. Since distribution of ventilation is very uneven in all of the studies, the errors in estimating $\mathrm{VA}_{\mathrm{A}_{2}}$ and $L_{2}$ are not large, and reasonably good estimates of $L_{T}$ can also be made. The distribution of ventilation was purposely kept uneven to avoid the introduction of other errors discussed by Nye (6).

Data in patients with chronic obstructive lung disease. Nitrogen washouts were performed in 18 people with advanced chronic obstructive lung disease. The diagnosis was based on history, physical examination, $\mathrm{X}$-ray examinations, and the presence of abnormally low values for maximum breathing capacity, timed vital capacity, and maximum expiratory flow rates in all patients. Nitrogen washout was performed and analyzed by methods similar to those used for the model. The data obtained from nitrogen washouts, as well as the results of some of the other pulmonary function studies on these patients, are given in Table II.

For the purpose of the present discussion only the average values of volume and ventilation need be considered. The following assumptions are made. (a) After correction for nitrogen eliminated by the tissues, the so-called "slow space" is a group of alveoli that behave homogeneously with respect to their elimination of nitrogen. The volume and effective or alveolar ventilation of this group of alveoli are referred to as $L_{2}$ and $\nabla_{A_{2}}$, respectively. (b) The "fast spaces" are here also considered to behave homogeneously. The volume and alveolar ventilation of these "spaces" are referred to as $L_{1}$ and $\mathrm{V}_{\mathrm{A}_{1}}$ respectively. (c) Ventilation is continuous. The validity of these as- 
sumptions have been discussed at length in the literature. (d) The initial concentration of nitrogen is equal to $80 \%$ throughout the lung. This assumption does not significantly influence the comparison between parallel and asynchronous ventilation.

To assess the effect that gas transfer between the groups of alveoli might have on the parallel

A

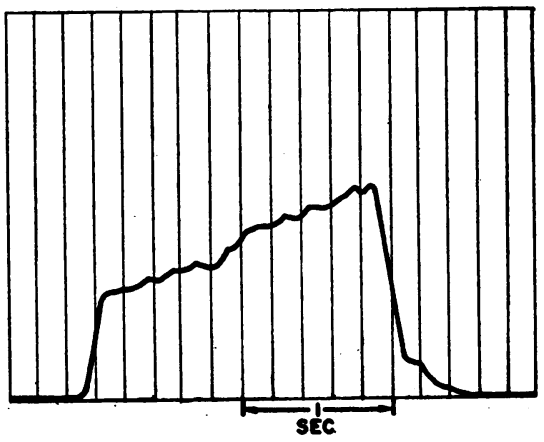

\% $\mathrm{N}_{2}$, MOUTH
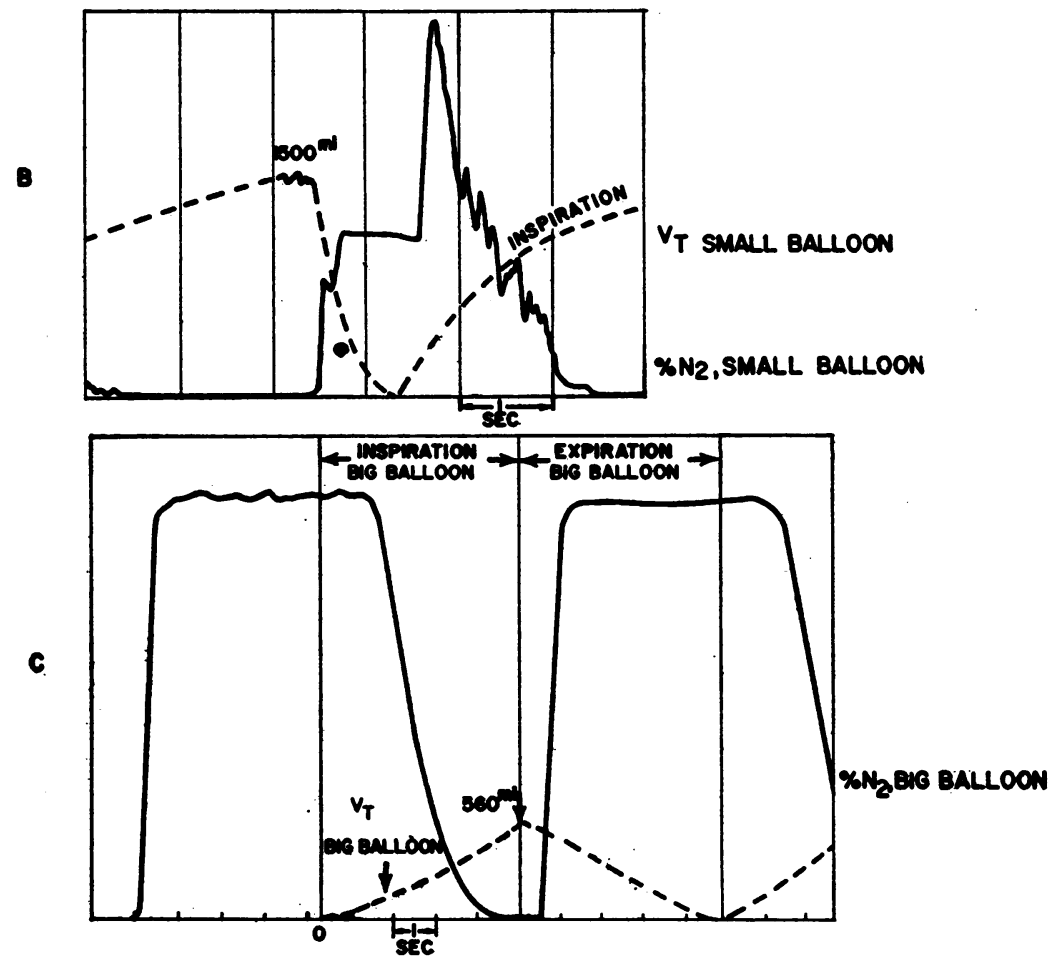

Fig. 6. Course of the changing Nitrogen CONCENTRATion DURING NitroGEN WASHOUT IN THE EXPERIMENTAL MODEL. A, The constantly rising exipratory nitrogen concentration at the common outlet (mouth). B, Nitrogen concentration recorded at the junction of the small balloon with its own dead space. On expiration nitrogen concentration rises sharply to a plateau value which represents the concentration of nitrogen within the balloon. With onset of inspiration the plateau continues momentarily (reinspired separate dead space gas) then nitrogen concentration rises sharply to a peak which gradually falls to zero. This large increase in inspired nitrogen is caused by gas transferred from the large balloon. C, Nitrogen concentration recorded at the junction of the large balloon with its own dead space. Nitrogen concentration rises sharply to a plateau equalling the nitrogen concentration within the balloon. After the balloon reinspires its own dead space gas, nitrogen concentration falls to zero. 

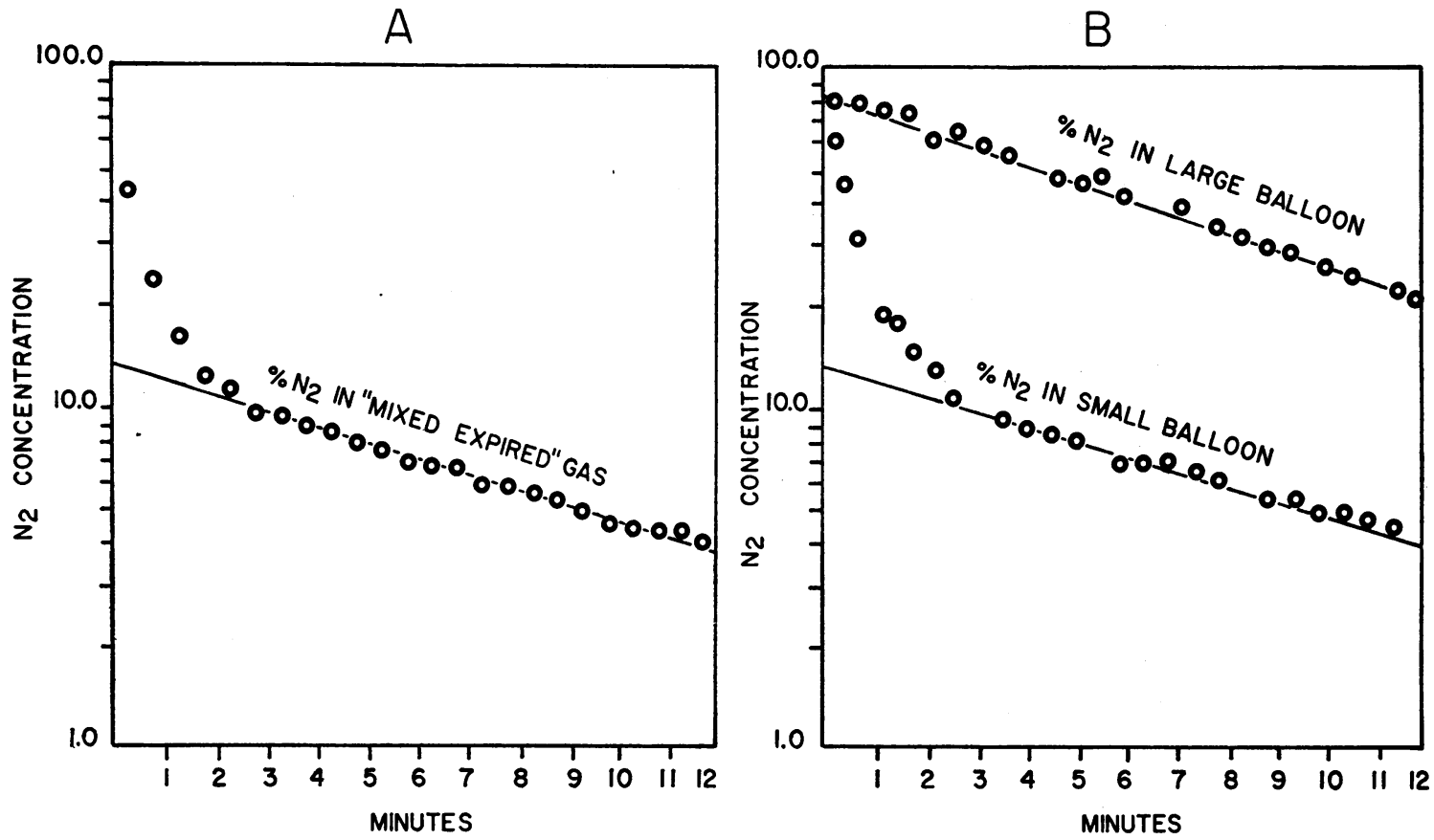

Fig. 7. Time course of Nitrogen elimination in the experimental model. A, The semilogarithmic plot of mixed expired nitrogen and $B$, the semilogarithmic plot of nitrogen in each balloon.

TABLE I

Data on ventilation, Pendelluft, and volume in the experimental model

\begin{tabular}{|c|c|c|c|c|c|c|c|c|c|c|}
\hline \multirow{4}{*}{$\begin{array}{c}\text { Study } \\
1\end{array}$} & \multirow{4}{*}{$\begin{array}{l}F \\
6\end{array}$} & \multirow{4}{*}{$\frac{\dot{\mathrm{V}}_{\mathrm{E}}}{10.44}$} & \multirow{3}{*}{\multicolumn{2}{|c|}{$\frac{\mathrm{V}_{\mathrm{A}_{1}}}{\text { liters } / \min }$}} & \multirow{3}{*}{$\dot{\mathrm{V}}_{\mathrm{A}_{2}}$} & \multirow{3}{*}{$L_{1}$} & \multirow{3}{*}{$\begin{array}{l}L_{2} \\
\text { liters }\end{array}$} & \multirow{3}{*}{$L_{T}$} & \multirow{2}{*}{\multicolumn{2}{|c|}{$\frac{\text { Pendelluft }}{L_{1} \text { to } L_{2} L_{8} \text { to } L_{1}}$}} \\
\hline & & & & & & & & & & \\
\hline & & & & & & & & & liter & $\min$ \\
\hline & & & $\begin{array}{l}\text { M } \\
\text { WO }\end{array}$ & $\begin{array}{l}8.42 \\
6.32\end{array}$ & $\begin{array}{l}\text { M } 1.90 \\
\text { WO } 2.32\end{array}$ & $\begin{array}{l}\text { M } 4.64 \\
\text { WO } 3.79\end{array}$ & $\begin{array}{l}\text { M } 16.41 \\
\text { WO } 18.15\end{array}$ & $\begin{array}{l}\text { M } 21.05 \\
\text { WO } 21.94\end{array}$ & 0.30 & 1.38 \\
\hline 2 & 6 & 10.36 & $\begin{array}{l}\text { M } \\
\text { WO }\end{array}$ & $\begin{array}{l}8.38 \\
6.24\end{array}$ & $\begin{array}{l}\text { M } 1.90 \\
\text { WO } 2.32\end{array}$ & $\begin{array}{l}\text { M } 4.67 \\
\text { WO } 3.16\end{array}$ & $\begin{array}{l}\text { M } 16.54 \\
\text { WO } 18.34\end{array}$ & $\begin{array}{l}\text { M } 21.21 \\
\text { WO } 21.50\end{array}$ & 0.32 & 1.41 \\
\hline 3 & 6 & 9.44 & $\begin{array}{l}\text { M } \\
\text { WO }\end{array}$ & $\begin{array}{l}6.52 \\
5.60\end{array}$ & $\begin{array}{ll}\text { M } & 2.04 \\
\text { WO } 1.97\end{array}$ & $\begin{array}{l}\text { M } 4.56 \\
\text { WO } 3.86\end{array}$ & $\begin{array}{ll}\text { M } & 16.14 \\
\text { WO } & 16.96\end{array}$ & $\begin{array}{l}\text { M } 20.70 \\
\text { WO } 20.82\end{array}$ & 0.33 & 0.99 \\
\hline 4 & 6 & 11.43 & $\begin{array}{l}\text { M } \\
\text { WO }\end{array}$ & $\begin{array}{l}9.22 \\
7.74\end{array}$ & $\begin{array}{ll}\text { M } & 1.79 \\
\text { WO } & 1.89\end{array}$ & $\begin{array}{l}\text { M } 4.73 \\
\text { WO } 2.37\end{array}$ & $\begin{array}{l}\text { M } 16.15 \\
\text { WO } 17.06\end{array}$ & $\begin{array}{lr}\text { M } & 20.88 \\
\text { WO } & 19.43\end{array}$ & 0.34 & 1.04 \\
\hline 5 & 6 & 11.21 & $\begin{array}{l}\text { M } \\
\text { WO }\end{array}$ & $\begin{array}{l}9.42 \\
7.62\end{array}$ & $\begin{array}{ll}\text { M } & 1.65 \\
\text { WO } 1.79\end{array}$ & $\begin{array}{l}\text { M } 4.65 \\
\text { WO } 3.04\end{array}$ & $\begin{array}{lr}\text { M } & 16.22 \\
\text { WO } 17.54\end{array}$ & $\begin{array}{l}\text { M } 20.87 \\
\text { WO } 20.58\end{array}$ & 0.47 & 1.19 \\
\hline 6 & 6 & 8.40 & $\begin{array}{l}\text { M } \\
\text { WO }\end{array}$ & $\begin{array}{l}4.79 \\
1.98\end{array}$ & $\begin{array}{l}\text { M } 4.18 \\
\text { WO } 4.62\end{array}$ & 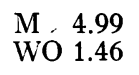 & $\begin{array}{ll}\text { M } & 16.71 \\
\text { WO } & 18.48\end{array}$ & $\begin{array}{l}\text { M } 21.60 \\
\text { WO } 19.94\end{array}$ & 0.49 & 1.88 \\
\hline 7 & 12 & 14.95 & $\begin{array}{l}\text { M } 1 \\
\text { WO } 1\end{array}$ & $\begin{array}{l}11.56 \\
10.54\end{array}$ & $\begin{array}{ll}\text { M } & .81 \\
\text { WO } & .81\end{array}$ & $\begin{array}{l}\text { M } 4.99 \\
\text { WO } 4.57\end{array}$ & $\begin{array}{ll}\text { M } & 16.28 \\
\text { WO } & 16.22\end{array}$ & $\begin{array}{l}\text { M } 21.27 \\
\text { WO } 20.79\end{array}$ & 0.35 & 0.67 \\
\hline 8 & 10 & 15.55 & $\underset{\text { WO }}{\text { M }} 1$ & $\begin{array}{r}11.73 \\
7.82\end{array}$ & $\begin{array}{l}\text { M } 4.78 \\
\text { WO } 4.73\end{array}$ & $\begin{array}{l}\text { M } 5.20 \\
\text { WO } 4.30\end{array}$ & $\begin{array}{l}\text { M } 16.76 \\
\text { WO } 16.58\end{array}$ & $\begin{array}{l}\text { M } 21.96 \\
\text { WO } 20.88\end{array}$ & 2.37 & 1.59 \\
\hline 9 & 10 & 14.94 & M & 12.09 & 4.16 & 4.99 & 15.94 & 20.93 & 2.24 & 2.07 \\
\hline
\end{tabular}

F, ventilatory frequency; M, measured "actual" value (see text); WO, estimated from washout data. Other symbols are as defined in the text. $\dot{V} E$, minute expired ventilation; $\dot{V}_{\mathbf{A}_{1}}$ and $\dot{V}_{\mathbf{A}_{2}}$, effective expiratory ventilation of the well and poorly ventilated balloons respectively; $L_{1}$ and $L_{2}$, the volume of the well and poorly ventilated balloons respectively; $L_{T}$, the total volume of the two balloons. 
TABLE II

Data obtained in patients with chronic obstructive lung disease

\begin{tabular}{|c|c|c|c|c|c|c|c|c|c|c|c|c|}
\hline Study & Age & Subject & $\dot{\mathrm{V}} \mathbf{E}$ & $\dot{\mathrm{V}}_{\mathrm{A}_{2}}$ & $\dot{\mathrm{V}}_{\mathbf{A}_{1}}$ & $L_{2}$ & $L_{1}$ & $L_{T}$ & MBC & $L_{2} / L \mathrm{~T}$ & $\mathrm{SaO}_{2}$ & $\mathrm{PaCO}_{2}$ \\
\hline & & \multicolumn{4}{|c|}{ liters/min } & \multicolumn{2}{|c|}{ liters } & \multicolumn{2}{|c|}{ liters $/ \min$} & $\%$ & $\%$ & $m m H_{g}$ \\
\hline 1 & 55 & T.V. & 10.5 & 0.69 & 5.0 & 3.30 & 2.18 & 5.48 & 20 & 60 & 83 & 60 \\
\hline 2 & 60 & N.I. & 9.3 & 0.44 & 4.4 & 6.91 & 3.06 & 9.97 & 33 & 69 & 82 & 51 \\
\hline 3 & & L.A. & 8.1 & 1.07 & 4.0 & 4.05 & 1.94 & 5.99 & 29 & 67 & 83 & 51 \\
\hline 4 & 70 & M.P. & 8.0 & 0.43 & 6.2 & 3.84 & 2.32 & 6.15 & 16 & 62 & 85 & 61 \\
\hline 5 & 66 & M.R. & 9.9 & 0.81 & 6.2 & 4.10 & 1.86 & 5.96 & 22 & 69 & 85 & - \\
\hline 6 & & B.S. & 10.9 & 1.45 & 6.4 & 4.34 & 1.09 & 5.43 & 21 & 80 & 71 & 50 \\
\hline 7 & 46 & G.J. & 8.9 & 0.28 & 5.2 & 2.97 & 2.01 & 4.98 & 44 & 60 & 83 & 60 \\
\hline 8 & 46 & B.E. & 11.4 & 1.50 & 4.8 & 6.58 & 0.87 & 7.45 & 32 & 88 & 75 & 50 \\
\hline 9 & 44 & M.R. & 6.6 & 0.67 & 2.9 & 3.70 & 1.50 & 5.23 & 21 & 71 & 79 & - \\
\hline 10 & 83 & K.J. & 11.7 & 0.97 & 8.2 & 2.87 & 1.97 & 4.84 & 41 & 59 & 81 & 38 \\
\hline 11 & 73 & T.J. & 10.2 & 0.61 & 3.1 & 2.37 & 1.04 & 3.41 & 33 & 70 & 83 & 41 \\
\hline 12 & 43 & S.J. & 9.6 & 0.66 & 6.6 & 4.23 & 1.92 & 6.18 & 27 & 69 & 82 & 54 \\
\hline 13 & 62 & R.D. & 9.5 & 0.33 & 5.6 & 1.64 & 1.48 & 3.12 & - & 53 & 85 & 47 \\
\hline 14 & 52 . & G.A. & 10.0 & 0.21 & 3.6 & 1.97 & 1.74 & 3.71 & 31 & 53 & 65 & 52 \\
\hline 15 & 64 & D.G. & 13.4 & 1.13 & 8.4 & 3.72 & 1.17 & 4.89 & - & 76 & 83 & 43 \\
\hline 16 & 59 & R.J. & 7.23 & 0.76 & 3.15 & 5.10 & 0.83 & 5.96 & 23 & 86 & 77 & 49 \\
\hline 17 & & B.J. & 10.56 & 0.81 & 6.10 & 3.29 & 0.91 & 4.19 & - & 79 & 82 & 45 \\
\hline 18 & 65 & D.H. & 16.59 & 1.08 & 11.70 & 4.50 & 0.95 & 5.45 & 35 & 83 & 76 & 二 \\
\hline
\end{tabular}

$\dot{\mathrm{V}} \mathrm{E}$, minute ventilation; $\dot{\mathrm{V}}_{\mathrm{A}_{2}}$ and $\dot{\mathrm{V}}_{\mathbf{A}_{1}}$, alveolar ventilation of the slow and fast spaces respectively; $L_{2}$ and $L_{1}$, the volume of the slow and fast spaces respectively; $L_{T}$, functional residual volume; MBC, maximum breathing capacity; $\mathrm{Sa}_{\mathrm{O}_{2}}$, arterial oxygen saturation; $\mathrm{PaCO}_{2}$, arterial carbon dioxide tension.

ventilatory theory, we undertook the following procedure. We first assumed that the average values are correct, and then introduced a gas transfer flow rate and reanalyzed the data using equations 8-10 for "parallel ventilation." We used an arbitrary gas transfer flow rate $(\mathrm{Vp})$ of about $60 \%$ of $\mathrm{VA}_{2}$ for the following reasons. First, it is unlikely that ventilation is 180 degrees out of phase between poorly and well-ventilated alveoli or that ventilation is solely in series and therefore $V p_{1}$ or $V p_{2}$ must be less than $V A_{2}$ as previously discussed. Second, in the model experiments the Pendelluft averaged about $60 \%$ of $\mathrm{V}_{\mathrm{A}_{2}}$ when the distribution of ventilation was somewhat similar to that in the present average case of emphysema.
The distortions caused by V $\mathrm{V} p$ in the estimation of volume and ventilation and turnover rates are shown in columns B and C of Table III. These data suggest that if the assumptions underlying the analysis are correct, one may still be able to obtain relatively reliable information about the slow space and total lung volume (FRC) in patients with advanced chronic obstructive pulmonary disease.

\section{Discussion}

Several recent papers have discussed the effect of reinspiration of mixed dead space gas and Pendelluft on inert gas washout and closed-circuit equilibration using mathematical models.

TABLE III

Effect of interalveolar gas transfer on estimates of volume and ventilation in patients with chronic obstructive lung disease

\begin{tabular}{|c|c|c|c|}
\hline & $\begin{array}{c}A \\
\text { Assuming no gas } \\
\text { transfer } \\
\dot{\mathrm{V}} \mathrm{p}_{1}, \dot{\mathrm{V}} \mathrm{p}_{2}=0\end{array}$ & $\begin{array}{c}\mathrm{B} \\
\mathrm{V}_{\mathrm{p}_{1}}=\mathrm{V}_{\mathrm{p}_{2}}=0.5 \mathrm{liter} / \mathrm{min}\end{array}$ & $\begin{array}{c}\mathrm{C} \\
\mathrm{Vp}_{2}=0.5 \text { liter } / \mathrm{min}\end{array}$ \\
\hline $\begin{array}{l}\dot{\mathrm{V}}_{\mathrm{A}_{1}}, \text { liters } / \text { min } \\
\mathrm{V}_{\mathrm{A}_{2}}, \text { liters } / \text { min } \\
L_{1} \text {, liters } \\
L_{2} \text {, liters } \\
L_{T}, \text { liters } \\
\mathrm{V}_{\mathrm{A}_{1}} / L_{1}, \text { times } / \text { min } \\
\mathrm{V}_{\mathrm{A}_{2}} / L_{2}, \text { times } / \text { min }\end{array}$ & $\begin{array}{l}5.60 \\
0.80 \\
1.60 \\
3.80 \\
5.40 \\
3.50 \\
0.21\end{array}$ & $\begin{array}{l}4.58(-18 \%) \\
0.83(+4 \%) \\
1.30(-19 \%) \\
4.37(+15 \%) \\
5.67(+5 \%) \\
3.52(+.06 \%) \\
0.19(-9.5 \%)\end{array}$ & $\begin{array}{l}5.07(-9.5 \%) \\
0.83(+4 \%) \\
1.45(-9.5 \%) \\
3.95(+4 \%) \\
5.40(0 \%) \\
3.50(0 \%) \\
0.21(0 \%)\end{array}$ \\
\hline
\end{tabular}

The figures in parentheses are the approximate percentage by which a given parameter is over- or underestimated. 
Weber and Bouhuys (7) analyzed the effect of mixed dead space gas in a model in which two chambers were directly connected to a single common dead space, with ventilation considered a continuous process. They concluded that inert gas washout proceeded as the sum of three different exponential terms as opposed to the two exponentials in our analysis. Bouhuys (8) later proposed that the third exponential arose from the assumption that ventilation is continuous rather than cyclic, and that a similar theoretical model was presented by Wise and Defares (see below) using cyclic ventilation approaches equilibrium as the sum of the two exponentials. It seems more likely however that the third exponential arose because the authors included the dead space as a third chamber, which is completely washed out at the end of each inspiration during cyclic ventilation. The inclusion of the dead space as a third chamber is unnecessary but does not affect their results. It only makes their equations more difficult to solve.

Wise and Defares (9) considered the effect of mixed dead space on closed-circuit helium equilibration for cyclic and synchronous ventilation using two chambers with two separate dead spaces connected to a common dead space. They suggested a correction factor, based on an assumed distribution of dead space ventilation, to be applied to living subjects.

Nye (6) presented a two compartment model in which ventilation was cyclic. $\mathrm{He}$ analyzed, separately, the effects of both dead space and bidirectional Pendulluft on the apparent volumes and effective ventilations of the two compartments during closed-circuit helium equilibration and open circuit washout. Our conclusions concerning the apparent size and ventilation of the two compartments are identical with his.

No one has previously considered the possibility of unidirectional intercompartmental gas transfer. Although it is interesting to note that in most of the experiments with the physical model gas was transferred from the slow to fast space only, whether unidirectional transfer occurs in real lungs is of course unknown.

Evidently, gas transfer between groups of alveoli would have an effect on the composition of alveolar air during steady-state breathing, which is not apparent from analysis of expired air and arterial blood. For any given distribution of perfusion the well-ventilated alveoli would have a higher concentration of carbon dioxide and a lower concentration of oxygen than estimated by the usual methods. The reverse would be true of the poorly ventilated alveoli, if gas transfer was bidirectional. It is therefore possible that the so-called "overventilation" of the "fast spaces" of patients with obstructive lung disease is of greater importance in maintaining arterial carbon dioxide and oxygen tensions than has been previously stressed. Ross and Farhi (10) have already discussed the manner in which inspiration of mixed dead space gas tends to equalize the gas concentrations in groups of alveoli with different ventilation perfusion ratios.

We are not arguing that the lungs in chronic obstructive disease are really composed of only two homogeneous compartments. We only say that even if such lungs could be reduced to the simplest physiological model, interalveolar gas transfer would, in varying degrees, distort the analysis of such a model by the usual inert gas washout techniques. Even more sophisticated methods of studying the regional distribution of ventilation with radioactive gases would be in error when closed-circuit equilibration is used to determine regional lung volumes. At present there is unfortunately no way of determining interalveolar gas transfer.

\section{Acknowledgments}

We gratefully acknowledge the technical assistance of Mr. Irving Jablon and Miss Louise Nobel.

\section{References}

1. Otis, A. B., C. B. McKerroe, R. A. Bartlett, J. Mead, M. B. McIlroy, N. J. Selverstone, and E. P. Radford, Jr. 1956. Mechanical factors in distribution of pulmonary ventilation. J. Appl. Physiol. 8: 427 .

2. Martin, C. J., A. C. Young, and Koh Ishikawa. 1965. Regional lung mechanics in pulmonary disease. J. Clin. Invest. 44 : 906.

3. Robertson, J. S., W. E. Siri, and H. B. Jones. 1950. Lung ventilation patterns determined by analysis of nitrogen elimination rates; use of the mass spectrometer as a continuous gas analyzer. J. Clin. Invest. $29: 577$.

4. Emmanuel, G. E., and F. Moreno. 1966. Distribution of ventilation and blood flow during exercise in emphysema. J. Appl. Physiol. 21: 1532. 
5. Emmanuel, G., W. A. Briscoe, and A. Cournand. 1961. A method for the determination of the volume of air in the lungs: measurements in chronic pulmonary emphysema. J. Clin. Invest. 40:329.

6. Nye, R. E., Jr. 1961. Theoretical limits to measurement of uneven ventilation. J. Appl. Physiol. $16: 1115$.

7. Weber, J., and A. Bouhuys. 1959. Theoretical considerations on lung clearance. Acta Physiol. Pharmacol. Neerl. 8: 121.
8. Bouhuys, A. 1964. Distribution of inspired gas in the lungs. In Handbook of Physiology. Waverly Press Inc., Baltimore. Section 3. I: 715.

9. Wise, N. E., and J. G. Defares. 1959. A model for unequal ventilation of the lungs assuming a common dead space and two separate dead spaces. Bull. Math. Biophys. 21: 343.

10. Ross, B. B., and L. E. Farhi. 1960. Dead space ventilation as determinant in the ventilation-perfusion concept. J. Appl. Physiol. 15 : 363. 